\title{
Changes in Amorphous Hydrogenated Carbon Films by Ultraviolet and Infrared Laser Irradiation
}

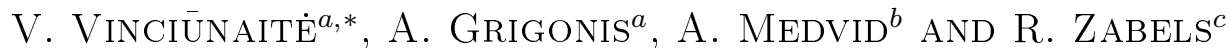 \\ ${ }^{a}$ Kaunas University of Technology, Studentụ St. 50, LT-51368 Kaunas, Lithuania \\ ${ }^{b}$ Riga Technical University, 14 Azenes Str., LV-1068 Riga, Latvia \\ ${ }^{c}$ Institute of Solid State Physics, University of Latvia, 8 Kengaraga St., LV-1063 Riga, Latvia
}

\begin{abstract}
Amorphous hydrogenated carbon films were formed on the Si (100) wafers by a direct-ion beam deposition method from pure acetylene and acetylene-hydrogen gas mixtures. The films were irradiated with a nanosecond Nd:YAG laser working at the first harmonics $\left(\lambda_{1}=1064 \mathrm{~nm}\right)$, the fourth harmonics $\left(\lambda_{4}=266 \mathrm{~nm}\right)$ or with a $\mathrm{Nd}: \mathrm{YVO}_{4}$ laser working at the third harmonic $\left(\lambda_{3}=355 \mathrm{~nm}\right)$. The films were studied by the Raman scattering, micro-Fourier transform infrared and Fourier transform infrared spectroscopies, null-ellipsometry, optical and scanning electron microscope, and Vickers hardness method. Irradiation by the wavelength $\lambda_{1}=1064 \mathrm{~nm}$ leads to graphitization and formation of the silicon carbide, because of the silicon substrate decomposition. The samples were strongly modified after the irradiation by $\lambda_{3}=355 \mathrm{~nm}$ - the thickness of the films decreased, and silicon carbide was formed. It was observed that nano-structured materials (e.g. carbon nano-onions, nc-diamond) were formed after the irradiation by $\lambda_{4}=266 \mathrm{~nm}$.
\end{abstract}

DOI: 10.12693 /APhysPolA.123.874

PACS: 79.20.Eb, 81.05.uj, 81.15.Jj, 82.80.Gk

\section{Introduction}

The effect of laser irradiation on the diamond-like carbon (DLC) films is determined by superposition of three processes: graphitization, spallation, and evaporation (including ablation) [1]. They are characterized by different threshold intensities [1] and their occurence depends on the laser parameters (pulse energy, energy density, pulse repetition rate $f$, beam shape, and wavelength), the optical (reflectivity, absorption coefficient) and thermophysical (heat capacity, density, thermal conductivity) properties of materials $[2,3]$. Controlling those three processes and other parameters, it is possible to create nanostructured carbon-based materials like: nanotubes, carbon nano-onions, nanocones, etc. $[1,2,4]$. In this work the influence of the laser parameters on the a-C:H films properties after the irradiation by a nanosecond pulsed laser will be discussed in detail.

\section{Experimental}

Amorphous hydrogenated carbon films (a-C:H) were formed on the $\mathrm{Si}(100)$ wafers by the ion beam deposition from pure acetylene and hydrogen $\mathrm{C}_{2} \mathrm{H}_{2} / \mathrm{H}_{2}$ gas mixtures. The thickness $d$, the refractive index $n$ and the extinction coefficient $k$ of layers were determined using a null-ellipsometer (Gaertner L117, He-Ne laser at $632.8 \mathrm{~nm}$ ). Ellipsometric parameters of non-irradiated samples were collected from different areas and average values of film thickness and optical constants $(n, k)$ were calculated for each sample. The B4 $(d=235 \mathrm{~nm}$,

*corresponding author; e-mail: vinga.vinciunaite@stud.ktu.lt $n=2.25, k=0.16)$ film was irradiated with a nanosecond Nd:YAG laser, working at the first harmonics $\left(\lambda_{1}=\right.$ $1064 \mathrm{~nm}, \tau=6 \mathrm{~ns}, f=12.5 \mathrm{~Hz}$ ) and the fourth harmonics $\left(\lambda_{4}=266 \mathrm{~nm}, \tau=3 \mathrm{~ns}, f=12.5 \mathrm{~Hz}\right)$. The other sample B3 $(d=60 \mathrm{~nm}, n=2.06, k=0.25)$ was irradiated with a Nd: $\mathrm{YVO}_{4}$ laser $\left(\lambda_{3}=355 \mathrm{~nm}, \tau=10 \mathrm{~ns}\right.$, $f=20 \mathrm{~Hz}$ ). The diameter of a laser beam spot was $6 \mathrm{~mm}$. Laser irradiation were done at atmospheric pressure at room temperature.

The a-C:H films were studied by the Raman scattering (RS) spectroscopy $(\lambda=532.3 \mathrm{~nm})$ in a wave number spectral range of $400-4000 \mathrm{~cm}^{-1}$. The RS spectra for the samples irradiated by $\lambda_{1}, \lambda_{3}$ were fitted by two Gaussian-shape lines in the spectral range $1000-2000 \mathrm{~cm}^{-1}$; fitting for the samples irradiated by $\lambda_{4}$ was not made, because of low intensity of the characterizing curves in the spectral range $1000-2000 \mathrm{~cm}^{-1}$. The position of the $G$ band and the full-width at half-maximum $\Delta G$ correspond to a crystalline graphite. $D$ peak position and $\Delta D$ correspond to the disorder of the $s p^{2}$ phase.

The micro-Fourier transform infrared ( $\mu$ FTIR) spectra were collected for the films irradiated by $\lambda_{4}$ in reflection mode using the FTIR spectrometer Vertex 70 coupled with an infrared microscope Hyperion 3000, the MCT single point detector in the spectral range 600$4000 \mathrm{~cm}^{-1}$. A total number of 128 interferograms were collected. The collected spectra of the samples with the $4 \mathrm{~cm}^{-1}$ resolution were rationed against a reference spectrum and transferred to absorption values. The FTIR (Spectrum GX, Perkin Elmer) spectra were measured for $\lambda_{3}$ in a reflection mode in the spectral range 650$4000 \mathrm{~cm}^{-1}$.

The surface morphology was analyzed by the scaning electron microscope, SEM (JSM6490LV), the optical microscope (Olympus BX51). The microhardness and 
Young modulus $E$ were measured by the Vickers hardness method, VH (MTS G200 nanoindenter with a Berkovich diamond tip). The crystal size $L_{\mathrm{a}}$ was obtained using equation given by Cançado et al. [5].

\section{Results and discussion}

The obtained by ellipsometry values of optical constants and film thickness for the samples irradiated by $\lambda_{4}$ ranged in the following intervals: $n=1.8-2.7, k=$ $0-0.73, d=50-220 \mathrm{~nm}$; for the $\lambda_{3}$ irradiation: $n=1.87-$ 2.10, $k=0-0.06, d=37-137 \mathrm{~nm}$; for the $\lambda_{1}$ irradiation: $n=2.1-2.4, k=0.50-0.16, d \approx 170 \mathrm{~nm}$. These parameters were calculated by means of the program "Film Ellipse" using the most appropriate multilayer models: $\mathrm{DLC} / \mathrm{SiC} / \mathrm{Si}$ (or $\alpha-\mathrm{Si})$.

In the present investigations we used the a-C:H films with a band gap of $\approx 1.4-1.6 \mathrm{eV}[6]$. Just a small amount of photon energy $\left(\lambda_{1}=1064 \mathrm{~nm}, E \approx 1.17 \mathrm{eV}\right)$ is absorbed by free electrons that transfer the residual energy to a crystal lattice within $\approx 1^{-10} \mathrm{~s} \mathrm{[2]}$. Such a process leads to the heating of the film and graphitization. The calculated penetration depth of laser light $(530 \mathrm{~nm})$ is larger than the film thickness $(\approx 235 \mathrm{~nm})$, and consequently, the main part of the energy is absorbed by the silicon substrate $\left(E_{\mathrm{g}} \approx 1.12 \mathrm{eV}\right)$ causing the destruction of the $\mathrm{Si}-\mathrm{Si}$ bonds. The silicon carbide $(\mathrm{SiC})$ layer $(d \approx 10 \mathrm{~nm})$ was formed in the interface between the $\mathrm{a}: \mathrm{C}-\mathrm{H}$ film and the silicon substrate because of the diffusion of the silicon into the film. The earlier results have shown that there are no significant changes increasing the irradiation intensity $\left(35 \rightarrow 70 \mathrm{MW} / \mathrm{cm}^{2}\right)$ in the $\mathrm{a}: \mathrm{C}-\mathrm{H}$ films [7], only the thickness of the $\mathrm{SiC}$ changed $(d \approx 50 \mathrm{~nm})$. It was observed that nanostructured materials were not formed using $\lambda_{1}$.

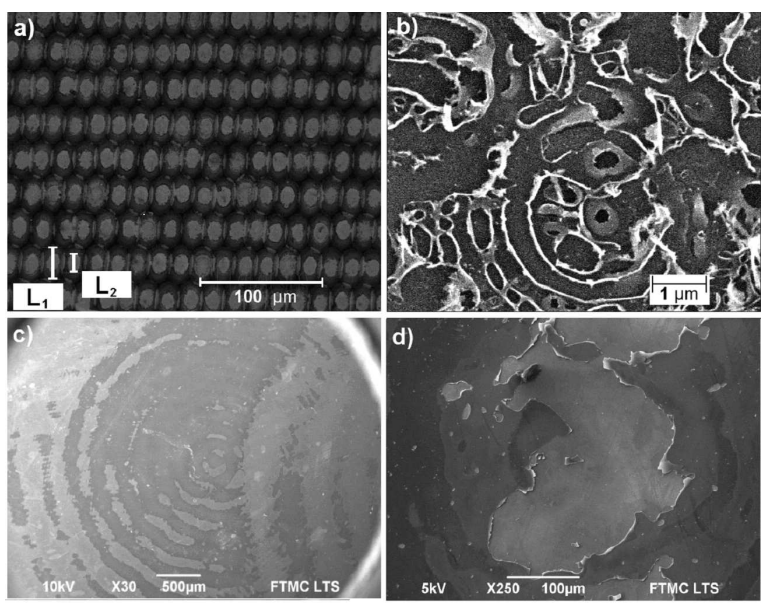

Fig. 1. Surface morphology of the B3 sample after two pulses with $8 \mathrm{MW} / \mathrm{cm}^{2} . \quad L_{1}=25.69 \mu \mathrm{m}$ and $L_{2}=$ $15.46 \mu \mathrm{m}(\mathrm{a})$, SEM image after irradiation by $\lambda_{3}$ (b); SEM image of the B4 sample after two (c) and four (d) pulses.

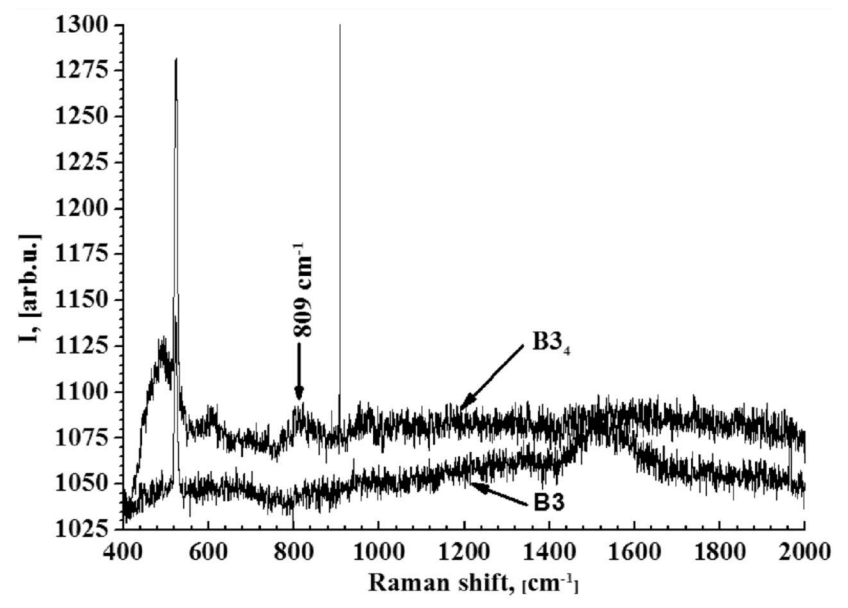

Fig. 2. Comparison of two RS spectra in spectral range 400-2000 $\mathrm{cm}^{-1}$ for the non-irradiated B3 sample and the sample B $3_{4}$ irradiated by eight $\lambda_{3}$ pulses per spot (irradiation intensity of $8 \mathrm{MW} / \mathrm{cm}^{2}$ ).

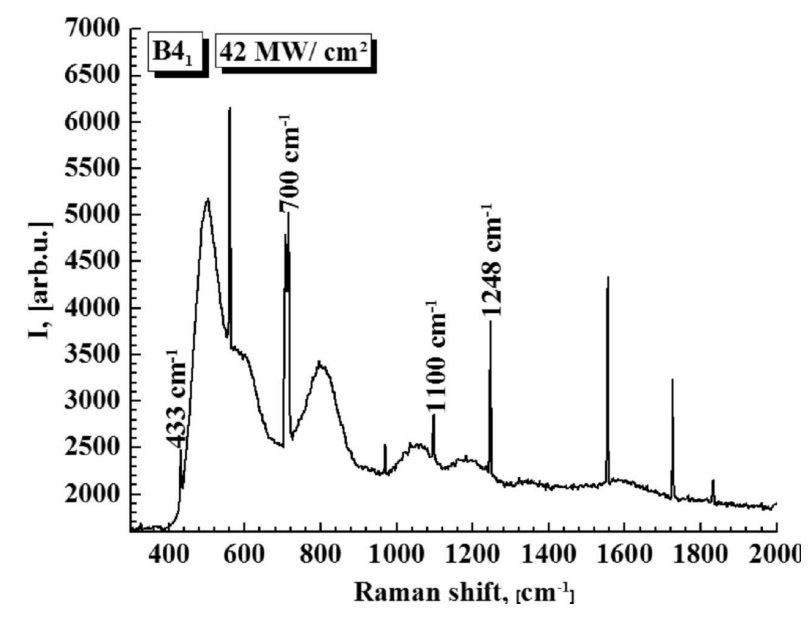

Fig. 3. RS spectra in spectral range $400-2000 \mathrm{~cm}^{-1}$ for the $\mathrm{B} 4_{1}$ film after four pulse irradiation by $\lambda_{4}$.

The irradiation by the $\lambda_{3}$ laser $(355 \mathrm{~nm}, E \approx 3.48 \mathrm{eV}$; penetration depth $\approx 113 \mathrm{~nm}$ ) caused ablation of the films that is not homogeneous over the laser beam diameter (Fig. 1a). Moreover, a strong spallation took place (Fig. 1b). The evaporation of the surface occurred and resulted in the decrease of the a:C-H film thickness $(60 \rightarrow 45 \mathrm{~nm})$ and $\mathrm{SiC}$ was formed $\left(\mathrm{B}_{4}, \approx 800 \mathrm{~cm}^{-1}\right.$, Fig. 2) [8, 9]. Increasing the irradiation intensity and pulses number per spot (Fig. 2, Table) the weak bonds (e.g. $\mathrm{C}-\mathrm{H}, \mathrm{C}-\mathrm{C}$ ) are destroyed leading to hydrogen diffusion into the silicon substrate and evaporation from the film surface. The decrease in the hydrogen content increases the probability to form the graphite layers in the film. Moreover, for the destruction of the $\mathrm{C}=\mathrm{C}$ bonds more energy is needed - the graphitization process becomes dominating in the a-C:H films as a result (Table): the $G$ peak shifts to the higher wave number position 
$1532 \rightarrow 1582 \mathrm{~cm}^{-1}$ and the intensity of the $D$ peak increases. 8 pulses per spot at the irradiation intensity $8 \mathrm{MW} / \mathrm{cm}^{2}$ leads to ablation of the whole a-C:H surface (Fig. 2). The FTIR results prove it: there were not found any traces of: $s p^{3}$ configuration $\mathrm{CH}_{2}$ symmetric $(\mathrm{S})$, asymmetric $(\mathrm{A}), \mathrm{CH}$ vibrations $\left(s p^{3} \mathrm{CH}_{2} \mathrm{~S}, \mathrm{~A}\right.$; $\mathrm{CH}), s p^{3} \mathrm{CH}_{3} \mathrm{~A}[7]$.

Fitting parameters of the RS spectra, VH results and main laser irradiation parameters for $\lambda_{3}$.

TABLE

\begin{tabular}{c|c|c|c|c|c|c|c|c|c|c|c}
\hline \hline Sample & $\begin{array}{c}\lambda \\
{[\mathrm{nm}]}\end{array}$ & $\begin{array}{c}\text { Pulses } \\
\text { per } \\
\text { spot }\end{array}$ & $\begin{array}{c}\text { Irradiat. } \\
\text { intensity } \\
{\left[\mathrm{MW} / \mathrm{cm}^{2}\right]}\end{array}$ & $\begin{array}{c}D \\
{\left[\mathrm{~cm}^{-1}\right]}\end{array}$ & $\begin{array}{c}\Delta D \\
{\left[\mathrm{~cm}^{-1}\right]}\end{array}$ & $\begin{array}{c}G \\
{\left[\mathrm{~cm}^{-1}\right]}\end{array}$ & $\begin{array}{c}\Delta G \\
{\left[\mathrm{~cm}^{-1}\right]}\end{array}$ & $I_{\mathrm{D}} / I_{\mathrm{G}}$ & $\begin{array}{c}L_{\mathrm{a}} \\
{[\mathrm{nm}]}\end{array}$ & $\begin{array}{c}\mathrm{VH} \\
{[\mathrm{GPa}]}\end{array}$ & $\begin{array}{c}E \\
{[\mathrm{GPa}]}\end{array}$ \\
\hline $\mathrm{B} 4$ & - & - & - & 1319 & 230 & 1540 & 169 & 0.42 & 45.77 & 23 & 209 \\
$\mathrm{~B} 3$ & - & - & - & 1288 & 148 & 1532 & 155 & 0.32 & 60.08 & 24 & 206 \\
$\mathrm{~B} 33_{1}$ & & 2 & 8 & 1256 & 285 & 1586 & 111 & 1.65 & 11.65 & - & \\
$\mathrm{B} 33_{2}$ & 355 & 2 & 4 & 1336 & 268 & 1582 & 111 & 1.58 & 12.16 & - & \\
$\mathrm{B} 34$ & & 8 & 8 & - & - & - & - & - & - & - & \\
\hline
\end{tabular}

Not only heating of film surfaces was caused by the $\lambda_{4}$ irradiation (4.67 eV, penetration depth $132 \mathrm{~nm}$ ), but also graphitization, spallation and ablation processes occurred (Fig. 1c,d). It was observed that a large number of nanostructures was formed after the irradiation: $\mathrm{SiC}$, nc-diamond (Fig. 3, at $\approx 1250 \mathrm{~cm}^{-1}$ ) [10]; carbon nano-onions [11] were found in the $\mathrm{B} 4_{1}$ sample (Fig. 3, at $433,700,1100 \mathrm{~cm}^{-1}$ ) that caused the increase of refractive indices. The results proving the formation of those nanostructures will be discussed in the near future.

Also amorphous phases were strongly expressed: $\alpha$-Si, $\mathrm{SiO}_{x}, \mathrm{SiC}$, trans-polyacetylene $\omega_{1}\left(\right.$ trans- $\left.(\mathrm{CH})_{x}\right) \mathrm{C}-\mathrm{C}$ stretching mode [12], respectively, $\approx$ 494, 600, 800, $1060 \mathrm{~cm}^{-1}$ (Fig. 3).

Main sharp peaks were found at $\approx 2849 \mathrm{~cm}^{-1}$, $\approx 2922 \mathrm{~cm}^{-1}, \approx 2951 \mathrm{~cm}^{-1}$ in the $\mu$ FTIR reflection spectra for all samples irradiated by $\lambda_{4}$. The first two sharp peaks correspond to the $s p^{3} \mathrm{CH}_{2} \mathrm{~S}, \mathrm{~A}$ and $\mathrm{CH}$, respectively; the third one corresponds to the $s p^{3} \mathrm{CH}_{3} \mathrm{~A}$. The other functional groups were found for the $\mathrm{B} 3_{x}, \mathrm{~B} 4_{x}$ samples irradiated by the ultraviolet laser: $\mathrm{C}=\mathrm{O}, \mathrm{SiC}$ or $\mathrm{SiO}_{2}, \mathrm{Si}-\mathrm{CH}_{3}$ or $s p^{2}, s p^{3}$ configuration $\mathrm{C}-\mathrm{C} ; \mathrm{SiO}, \mathrm{S}-\mathrm{O}$ and etc. These data prove the formation of $\mathrm{SiC}$ and nc-diamond.

It was observed that the hardness decreased $(23 \rightarrow$ 17-19 GPa) after irradiation by $\lambda_{1}$ because the irradiation leads to the decrease of the hydrogen content in the film. HV measurements for the samples irradiated by $\lambda_{3}, \lambda_{4}$ were inappropriate, because of the strong changes (reduced adhesion with the silicon substrate, strong fragmentation of the DLC coatings) in the film surface.

\section{Conclusions}

Weak graphitization and $\mathrm{SiC}$ formation in the $\mathrm{DLC} / \mathrm{Si}$ interface were observed using infrared laser irradiation. The most destructive irradiation took place when the penetration depth was greater than the film thickness. Strong graphitization, spallation and ablation processes were caused by the ultraviolet laser irradiation. SiC layers were created in all samples and the presence of the nanocrystalline fractions (nc diamonds, carbon nano-onions, nc-SiC) was confirmed after the ultraviolet laser irradiation.

\section{Acknowledgments}

The article was prepared under support of the European Social Fund Agency (project No. VP1-3.1-ŠMM-08-K-01-013).

\section{References}

[1] A. Grigonis, Z. Rutkuniene, A. Medvids, Vacuum 82, 1212 (2008).

[2] Q. Wei, J. Narayan, J. Int. Mater. Rev. 45, 133 (2000).

[3] N.B. Dahotre, Lasers in Surface Engineering, ASM Internat., Scarborought 1998.

[4] D. Roy, Manish Chhowalla, H Wang, N. Sano, I. Alexandrou, T.W. Clyne, G.A.J. Amaratunga, J. Chem. Phys. Lett. 373, 52 (2003).

[5] L.G. Cançado, K. Takai, T. Enoki, M. Endo, Y.A. Kim, H. Mizusaki, A. Jorio, L.N. Coelho, R. Magalhães-Paniago, M.A. Pimenta, J. Appl. Phys. Lett. 88, 163106 (2006).

[6] M. Silinskas, A. Grigonis, J. Diam. Rel. Mat. 11, 1026 (2002).

[7] A. Grigonis, Z. Rutkuniene, V. Vinciunaite, Acta Phys. Pol. A 120, 26 (2011).

[8] F.-K. Tung, E. Perevedentseva, P.-W. Chou, C.-L. Cheng, J. Appl. Surf. Sci. 252, 1167 (2005).

[9] J.R. Shi, X. Shi, Z. Sun, E. Liu, H.S. Yang, L.K. Cheah, X.Z. Jin, J. Phys., Condens. Matter 11, 5111 (1999).

[10] L.V. Saraf, K.J. Bunch, M.H. Engelhard, P.L. Gassman, in: NANO'08, Ed. N.J. Piscataway, IEEE, New York 2008, p. 813.

[11] G. Davidson, Spectroscopic Properties of Inorganic and Organometallic Compounds, Vol. 37, Royal Soc. Chem., London 2005.

[12] M. Rybachuk, A. Hertwig, M. Weise, M. Sahre, M. Männ, U. Beck, J.M. Bell, Appl. Phys. Lett. 96, 211909 (2010). 